\title{
The lessons learned from conducting a condition survey on unsealed roads surfaced with marginal materials in the Iringa region, Tanzania
}

\author{
R. R. Mwaipungu \& D. Allopi \\ Department of Civil Engineering and Surveying, \\ Durban University of Technology, South Africa
}

\begin{abstract}
The data from the road condition survey has a number of applications, some of these are to determine optimal grading and reshaping frequencies. However, due to the number of variables contributing to the performance of gravel roads, each road organization has to record the characteristics of the distress on the gravel roads in their locality. This is due to the fact that variables behind distress formulation are not readily transferable from one geographical location to the other. This is the case, particularly if the locations in question differ in climatic condition, gravel material characteristics, quality of construction and maintenance, terrain, traffic characteristics and driver behaviours.

This paper has focused on the condition survey done on gravel roads in the Iringa region. The survey was part of the research to establish a gravel loss prediction model ideal for local application.

The results of the condition survey came out with, among other things, a new range of grading coefficient to suit the local marginal materials used for surfacing gravel roads in the Iringa region.

Keywords: Iringa region, condition survey, distress, performance, gravel loss, gravel roads, characteristics, marginal materials, extent, severity.
\end{abstract}




\section{Introduction}

\subsection{Condition survey as a tool of maintenance management systems (MMS)}

The basic purpose of maintenance management systems is to capture information about maintenance activities performed, and resources utilised. The system further provides maintenance engineers and managers with the information and analytical tools needed to allow them to make an educated guess (Whight et al. [1]). Typical features of an MMS include but are not limited to: i) development of an annual work program; ii) budgeting and allocating resources; iii) work authorization; iv) performance evaluation; and v) fiscal control (Whight et al. [1], Kendrick et al. [2], Underwood [3]). From the above it is noted that the visual condition survey is among the tools of MMS.

\section{Visual condition survey}

Michigan Technological University [4] states that a visual condition survey is the process of collecting data to determine the structural integrity, distress, and overall riding quality of the pavement. They further point out that condition surveys provide a rational method of allocating limited resources. The visual assessment is most applicable for determining re-gravelling requirements, grading frequencies, whether the gravel material on the road is suitable for the prevailing traffic volume and environment, and what type of distress is typical on the gravel road in question (Jones and Paige-Green [5]). Surface distress is damage observed on the pavement surface. Distress is the measure mostly used by maintenance personnel to determine the where, when, and what type of maintenance is required.

\subsection{Attributes of gravel road distress}

The appearance of gravel road distress is varied and often extremely complex. In this study, the task of describing this distress was achieved by recording its main characteristics - the so-called attributes of distress. The attributes referred to are: 1) type, 2) degree, and 3) extent. These are described as follows:

1) Type of distress. Common types of distress encountered on gravel roads under study are: gravel loss; potholes; rutting; erosion; corrugation; loose materials; stoniness; and dust. These were assessed together with material properties, road profile, riding quality and drainage.

2) Degree. The degree of a particular type of distress is a measure of its severity. This is particularly relevant for research purposes (Jones and Paige-Green [5]). The degree recorded gave the predominant severity of a particular type of distress. The most important categories of degrees are 1, 3, and 5 . If there is any uncertainty regarding the condition between degrees 1 and 3 or 3 and 5, the defect may be marked as 2 or 4 respectively.

3) Extent. The extent of distress is a measure of how wide spread the distress is over the length of the road segment. The extent is also indicated on a five-point scale in which the length of road affected by the distress is estimated as a 
percentage. Jones and Paige-Green [5] point out that the extent of the distress should be recorded only for that width of the road affecting the traffic.

\subsection{Visual assessment of the condition and performance of gravel roads}

Each $300 \mathrm{~m}$ long gravel road test section had its existing surface condition recorded on a data sheet, by walking along the test section and noting its type, severity and extent.

Table 1: Gravel road distresses recorded during the condition survey.

\begin{tabular}{|c|c|c|}
\hline Element & Distress & Conditions \\
\hline \multirow{14}{*}{ Carriageway } & Potholes & Degree: $0,1,2,3,4,5 ;$ Extent: $1,2,3,4,5$ \\
\hline & Rutting & Degree: $0,1,2,3,4,5 ;$ Extent: $1,2,3,4,5$ \\
\hline & Erosion-transverse & Degree: $0,1,2,3,4,5 ;$ Extent: $1,2,3,4,5$ \\
\hline & Erosion-longitudinal & Degree: $0,1,2,3,4,5 ;$ Extent: $1,2,3,4,5$ \\
\hline & Stoniness-embedded & Degree: $0,1,2,3,4,5 ;$ Extent: $1,2,3,4,5$ \\
\hline & Stoniness-loose & Degree: $0,1,2,3,4,5$; Extent: $1,2,3,4,5$ \\
\hline & Dustiness & Degree: $0,1,2,3,4,5$ \\
\hline & Loose material & Degree: $0,1,2,3,4,5 ;$ Extent: $1,2,3,4,5$ \\
\hline & Corrugation & Degree: $0,1,2,3,4,5$; Extent: $1,2,3,4,5$ \\
\hline & Slipperiness & Acceptable/Unacceptable \\
\hline & Skid resistance & Acceptable/Unacceptable \\
\hline & Trafficability & Acceptable/Unacceptable \\
\hline & Riding quality/safety & $\begin{array}{l}\text { Very good }(>80 \mathrm{~km} / \mathrm{h}) ; \text { Good }(80 \\
\mathrm{km} / \mathrm{h}) ; \text { Average }(60 \mathrm{~km} / \mathrm{h}) \text {, Poor }(40 \\
\mathrm{km} / \mathrm{h}) \text {, Very poor }(20 \mathrm{~km} / \mathrm{h})\end{array}$ \\
\hline & Road profile/shape & $\begin{array}{l}\text { Very good }(5 \%) \text {; Good }(2 \%) \text {; Flat; } \\
\text { Uneven; Very uneven }\end{array}$ \\
\hline \multicolumn{2}{|c|}{ Drainage from the road } & $\begin{array}{l}\text { Well above ground; Slightly above; } \\
\text { Level with ground; Slightly below; } \\
\text { Canal }\end{array}$ \\
\hline \multirow{2}{*}{ Material } & Gravel quality & $\begin{array}{l}\text { Very good; Good; Average; Poor; } \\
\text { Very poor }\end{array}$ \\
\hline & Gravel quantity & $\begin{array}{l}\text { Plenty; Sufficient; Isolated exposures; } \\
\text { Extensive exposures; None }\end{array}$ \\
\hline \multicolumn{2}{|c|}{ Gravel road performance } & $\begin{array}{l}\text { Very good; Good; Average; Poor; } \\
\text { Very Poor }\end{array}$ \\
\hline
\end{tabular}

The distresses that were recorded are as listed in Table 1. Following is a brief description of each distress assessed with the emphasis of its contribution to gravel loss.

1) Potholes. Are bowl shaped distress. Once pothole formation has been initiated (irrespective of the cause), drainage deteriorates and water ponds in the depressions. Enlargement of potholes by traffic occurs through compaction and 
remoulding of the weakened material (in the wet state) and removal of the material from the hole by vehicle wheels and splashing. Materials with a low soaked strength are thus likely to develop larger and deeper potholes in shorter periods (Pearson [6]) and accelerate gravel loss.

2) Rutting. These generally form as a result of gravel loss from the wearing course by traffic abrasion and by deformation of the subgrade and compaction of the wearing course (Pearson [6]). Ruts are assessed in terms of their capacity to retain water using a visual estimate of their average depth. The higher the severity degree of rutting is, the higher the effects of directional instability of a vehicle.

3) Erosion. Is the loss of gravel wearing course caused by the flow of water over the gravel road. The ability of a gravel material to resist erosion depends on its shear strength under the conditions in which the water flow occurs (Pearson [6]). Much of eroded gravel is deposited in the drains and culverts. Erosion of the wearing course also results in a change in the properties of the material as various fractions of the material are selectively removed. In this study, transverse and longitudinal erosions were quantified by their depth and width using a $2.0 \mathrm{~m}$ straight edge and wedge.

4) Stoniness-loose and embedded. Stoniness is the relative percentage of material in the road that is larger than the recommended maximum size of $37.5 \mathrm{~mm}$ (Pearson [6]). Stoniness was assessed by estimating the extent and severity. Figure 1 shows the variation of stones sizes in a gravel wearing course. The Figure reveals a lacks of control at the source of gravel materials before being delivered to the site.

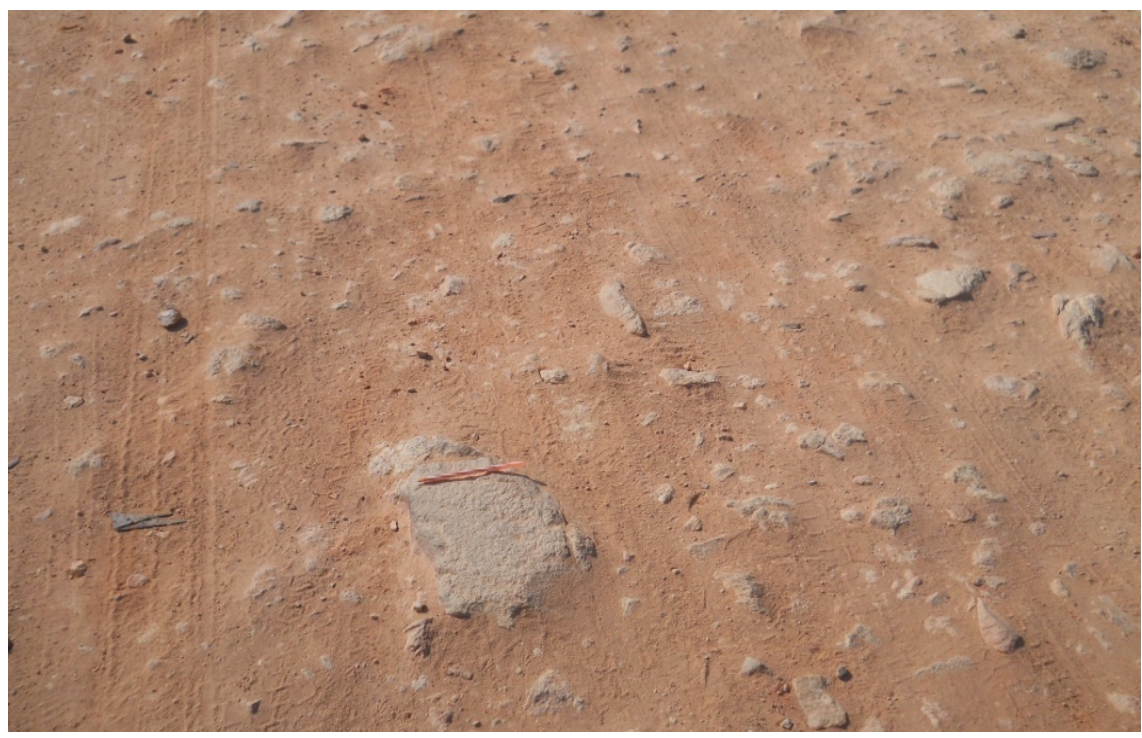

Figure 1: Stoniness embedment showing the variation in sizes of stones used for gravelling. 
5) Dustiness. Dust is the fine material released from the road under the wheels of moving vehicles and turbulence caused by vehicles and wind (Pearson [6]). Dust is one of the major sources of gravel loss. For assessment purpose, dust was rated in terms of three degrees, namely 1 which signifies no loss of visibility, 3 signifying some loss of visibility and 5 which is the dangerous loss of visibility. The higher the traffic volume the heavier the dust generated. The extent of dust is not normally estimated.

6) Loose material. This is formed by the ravelling of the wearing course material under traffic. It is mainly caused by a deficiency of fine material due to lack of cohesion, a poor particle size distribution (e.g. gap grading) in the wearing course materials; and inadequate compaction (Pearson [6]). Loose material was assessed by estimating its thickness variation across carriageway. Figure 2 shows the extent of ravelling in one of test sections along Iringa-Msembe road.

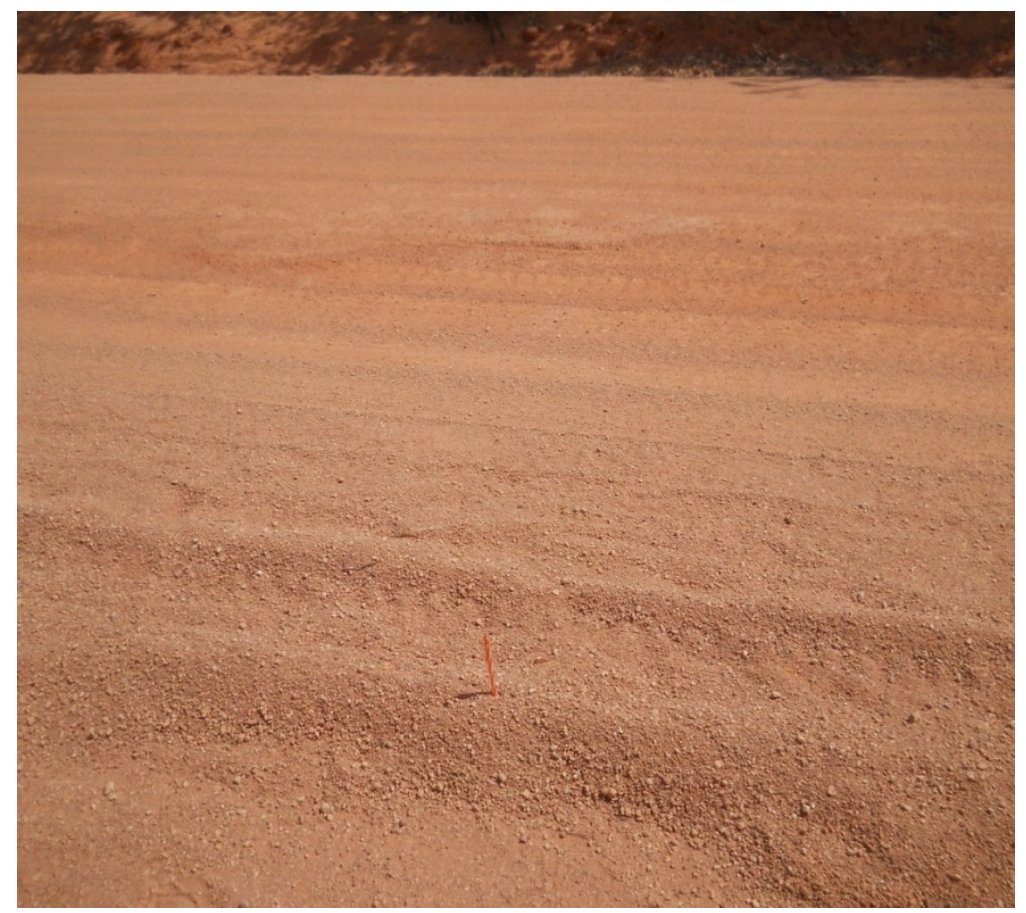

Figure 2: The extent of ravelling along Iringa-Msembe road.

7) Corrugation. Only low plasticity materials corrugate significantly, especially those with high sand and fine-gravel fractions.

8) Slipperiness and skid resistance. Slipperiness is the loss of traction caused by an accumulation of excessively fine or plastic material on the surface of the wearing course in wet conditions, while skid resistance is affected by the excess of loose, fine gravel (between 2 and $7 \mathrm{~mm}$ in diameter) that accumulates on the road surface through ravelling under traffic or poor grading practices during dry 
conditions (Pearson [6]). Slipperiness can often be evaluated by observing wheel tracks formed during wet weather. Wheel tracks retained in the road after drying. Skid resistance is evaluated in terms of the effect of loose material on vehicle stability, and the general impression gained while driving and braking on the dry road. Slipperiness and skid resistance were rated as either acceptable or unacceptable. The impression of wheel tracks reflected on gravel roads, indicate the quantity of gravel material lost on that particular road section.

9) Trafficability. The mechanism affecting trafficability is the loss of traction between the tyres and the road resulting from the low shear strength of the material. This results in churning of the material and sinking of the vehicles into the weak layer. Sandy materials are more prone to impassability when dry, while clayey materials become impassable when wet. For assessment purposes, trafficability was rated as either acceptable or unacceptable. The churning of the materials signify the loss of gravelling materials.

10) Riding quality and influencing factors. Defects influencing riding quality are: corrugation; loose material; stoniness; ruts; and erosion.

Riding quality is easily rated as a function of the estimated comfortable and safe driving speed (unaffected by geometric constraints or road width), and was interpreted as indicated in Table 2.

Table 2: Assessment of riding quality as recommended by the study.

\begin{tabular}{|c|c|l|}
\hline Rating & Descriptor & Description \\
\hline 1 & Very good & Estimated safe speed between 60 and $70 \mathrm{~km} / \mathrm{h}$ \\
\hline 2 & Good & Estimated safe speed between 50 and $60 \mathrm{~km} / \mathrm{h}$ \\
\hline 3 & Average & Estimated safe speed between 30 and $50 \mathrm{~km} / \mathrm{h}$ \\
\hline 4 & Poor & Estimated safe speed between 20 and $30 \mathrm{~km} / \mathrm{h}$ \\
\hline 5 & Very poor & Estimated safe speed $20 \mathrm{~km} / \mathrm{h}$ \\
\hline
\end{tabular}

11) Road profile/shape. A profile (shape) of a road has a major impact on gravel road performance. Gravel roads with a good profile tend to shed water rapidly avoiding the development of potholes and potentially impassable conditions. Where the profile is flat water tends to pond in localized depressions resulting in softening of the wearing course and the development of potholes. Failure to repair a flat road timeously will usually result in the development of ruts under traffic. These may become preferential water paths resulting in erosion, accelerated gravel loss and significant deterioration in riding quality.

12) Gravel quality. The properties contributing to good gravel are particle size distribution and cohesion. The gravel should have a range of particle sizes ranging from very fine up to about $40 \mathrm{~mm}$ in order to provide a strong framework of stones interlocked by a tight matrix of fines. Too many large stones result in poor riding quality and difficulties with maintenance. The fines need to have some plasticity to provide cohesion when dry. However, plasticity should not be so high that the road becomes slippery and impassable. 
13) Gravel quantity/layer thickness. Most gravel roads are constructed with a wearing course of about $150 \mathrm{~mm}$ thick of compacted gravel materials. Under traffic and environmental influences, this thickness gradually wears away and requires periodic replacement. If it is not replaced, the subgrade is exposed to traffic. The rate of gravel loss is a function of material properties, climate, and the traffic volume characteristics. However, as the traffic increases or the material quality deteriorates with time, this annual loss increase significantly. The rate also increases if profile and drainage are poor. In this study gravel quantity was physically measured on the road by excavating small holes in the wheel tracks, taking into account the material quality, traffic and any evidence of subgrade exposure. The exercise was conducted five times on a segment to determine a representative average for the segment. Output from the assessment was the millimetres of material remaining. The direct measurement of layer thickness is essentially a measure of the degree of severity of gravel loss, while estimation of the subgrade exposure represents an extent.

The height of stones above the surrounding road surface gives an indication of the amount of gravel materials that has been lost.

14) Gravel road performances. This is assessed primarily in terms of driver and passenger comfort and the driver's perception of safety. This is estimated after driving on the segment concerned before the detailed assessment is carried out in order to eliminate any bias that may result after completing the detailed assessment (Jones and Paige-Green [5]).

\section{Results of the condition survey of gravel roads under study}

At the beginning of the study in 2011, the total numbers of test sections were 25 . In the course of study, three sections were abandoned, two as the result of upgrading to sealed surface and one due to extensive vandalism on control points and benchmarks, which invalidated the gravel loss study.

The following is the general state of distressed conditions on test sections. Detail will follow under each road.

1) Slipperiness and skid resistance were at acceptable levels on all 22 test sections.

2) Trafficability was unacceptable on the Ndiwili and Itwanga test sections on the Iringa-Idete road. On the rest of the test sections, the trafficability was acceptable. 3) Drainage from the road was ranged from poor in those test sections with flat and uneven cross sections to average in those test sections with good cross-section. 4) Quality of marginal gravel materials employed as wearing course ranges from good to average. In this regard, the sections on each road fared as follows: IringaPawaga - six sections on had average quality and two had good quality; Iringa-Msembe - three sections had average quality and five sections had good quality; and Iringa-Idete - five sections had good quality, and three sections had average quality.

5) Gravel quantities which signify gravel loss were sufficient on all test sections, except at Kidete, Mapinduzi, and Muhunga on the Iringa-Idete road, and Mwika $\mathrm{B}$ on the Iringa-Msembe road where the quantities were at isolated exposure levels. 
6) The riding quality/safety for the current condition of gravel road alignment was good as the vehicles on almost all test sections could ride at $60 \mathrm{~km} / \mathrm{hr}$, except on sections with poor trafficability (Ndiwili and Itwanga), the speed ranged from average to poor $(50-30 \mathrm{~km} / \mathrm{h})$.

7) Transverse and longitudinal erosions on Igotikafu along the Iringa-Pawaga road the severity was at 3 degree. The Iringa-Msembe road had three test sections, which fared badly on erosion, Mangalali - had transverse erosion severity at 3 degree, while Mwika B and Nyamihuu, had longitudinal erosion severity of 4 and 3 degree respectively. The rest of the test sections on all three roads under study fared well due to being on self-draining terrain.

8) The gravel road's performance of all test sections were at 3 degree of severity, which is the border line between good and bad condition.

\subsection{The state of condition survey on Iringa-Msembe road}

The geological type of gravel materials employed for surfacing gravel roads on Mwika A and B, and Muhimbili and Nzihi roads are quartzitic brownish red or quartzitic silt stone respectively. The geologic type of gravel wearing course on Nyamihuu is brownish red lateritic and on Mangalali is grey mudstone. The gravel material's characteristics in terms of particle size distribution and shrinkage product met the requirements for marginal materials according to TZ-MoW [7], as $100 \%$ passed the $37.5 \mathrm{~mm}$ sieve, and shrinkage product range between 120 and 400. The grading coefficient (GC) for the gravelling materials in all test sections did not meet the requirement as per TZ-MoW [7], which range from 12-32. The $\mathrm{GC}$ for the test sections ranges from 36 to 72 inclusive. The climate prevailing on the test sections is moderate.

Apart from Mwika B, the rest test sections had their road profile in flat conditions. Nzihi and Muhimbili test sections had corrugations at 4 degree. Loose materials severity was at 4 degree on the Mwika A, Muhimbili and Nzihi test sections. Potholes on Mwika A was at 3 degree. Dustiness severity ranged from 3 to 4 degree, with the following five test sections at 4 degree, namely Mwika A, Mangalali, Muhimbili, Nzihi, and Nyamihuu, while one test section, Mwika B the severity was at 3 degree. The severity of longitudinal erosion was at 4 degree on Mwika B, and 3 degree on Nyamihuu test sections. Stoniness embedded with 4 degree of severity was prevalent on Mwika A, Mwika B, and Mangalali test sections.

These sections had fast changing surface condition due to the characteristic of gravel materials employed and high traffic volume travelling at a speed above $60 \mathrm{~km} / \mathrm{h}$ and lack of timely and appropriate maintenance. This phenomenon confirms Alzubaidi and Magnusson's statement [8] that the deterioration of gravel roads is governed by the behaviour of the gravel and roadbed materials, the drainage capacity, the combined action of traffic and climate and the absence of sufficient maintenance activities. 


\subsection{The state of the condition survey on Iringa-Idete road}

The major geological type of gravel material on the Iringa - Idete road is quartzitic. Two colours of quartzitic are predominant that is brownish grey for Tagamenda, Kitayawa, Igula and Ndiwili, and brownish red for Utengule, Itwanga, Amani and Ilamba. A brownish red quartzitic soil falls in to the wet climate condition, while brownish grey quartzitic falls in the moderate climate condition.

The gravel material's characteristics in terms of particle size analysis met the requirement of the specification for marginal materials as per TZ-MoW [7] for road works as $100 \%$ passed through a $37.5 \mathrm{~mm}$ sieve. The results of shrinkage product fared as follows: Tagamenda, Amani and Ilamba test sections did not meet the specified limits of SP. Tagamenda's wearing material's SP was below the minimum of 120, while Amani and Ilamba SP was above the maximum of 400. The remaining five sections, namely Kitayawa, Igula, Ndiwili, Italula and Itwanga were within 120-400, which is the set specification limits for SP. The average GC for Kitayawa and Igula test sections was 31 , which is on the higher side of the specified limit of 16-34. The remaining six test sections had a GC range of between 35 and 49 .

Prevalent distresses, with the degree of severity at 3 and 5 on these sections were poor cross section and dust.

\subsection{The state of the condition survey of Iringa-Pawaga road}

Gravel materials employed to surface unsealed road segments along IringaPawaga road have five types of geological characteristics. The main one is brownish grey quartzitic which was used to surface three sections, namely Kidete, Mapinduzi, and Kilendu. Light blue ferruginous siltstone surfaced Muhunga, brownish red lateritic surfaced Kimalanongwa test section, while grey limestone quartzitic surfaced Mkwambilenge, and brownish quartzitic surfaced Pawaga secondary school. The particle size distribution of marginal gravel materials employed for surfacing the test sections passes through a $37.5 \mathrm{~mm}$ sieve by $100 \%$, and had SPs ranging from 155 to 400 . Kimalanongwa and Kidete test sections had GC ranges between 28-32 and 23-31 respectively, hence meeting the TZ-MoW [7] condition. The remaining five test sections had GC ranges from 37-62, which is above the specified limits of $16-34$.

Four sections are in a dry climate, namely Muhunga, Kimalanogwa, Mkwambilenge, and Pawaga Secondary School, while three test sections are in moderate climates, namely Kidete, Mapinduzi, and Kilendu.

Prevalent distress on the test sections along Iringa-Pawaga road at 3 to 5 degree were road profile/shape, dustiness, rutting, loose aggregate, stoniness embedded and loose. The road profile/shape was flat in almost all test sections. Severity of dust was at 5 degree on road sections in the dry climatic area, while in the moderate area, the severity was at 3 degree. Loose aggregate was at 5 degree at Kidete, Mapinduzi, Kilendu, Umasaini (Muhunga), Mkwambilenge and Igotikafu. Stoniness embedded was 5 degree at Kidete, while Mapinduzi, Kilendu, Umasaini (Muhunga) were at 4 degree. Stoniness loose at Kilendu and Mwambilenge were 
at 5 degree and at Kidete, Muhunga and Igotikafu were at 4 degree. Rutting was at 5 degree at Mapinduzi and Mwambilenge, while at Igotikafu and Muhunga were at 4 degree. Rutting at Kilendu was at 3 degree. Potholes, transverse and, longitudinal erosions and corrugation are not prevalent on marginal gravel materials employed to surface the test sections along Iringa-Pawaga road.

\subsection{The state of the condition survey on Don-Bosco road}

The Don-Bosco road is under the management of Iringa Municipality Council. Generally, the road is being graded once annually. The traffic volume on this road is heavy, particularly during burial ceremonies as it accesses one of the major and busy grave yards in the municipality. Within two to three months after grading the road reverts to a bad condition.

The prevalent distress on this section is stoniness embedded, which start to protrude just weeks after grading and force vehicles to seek refuge on the shoulder or pedestrian walkway as shown in Figure 3.

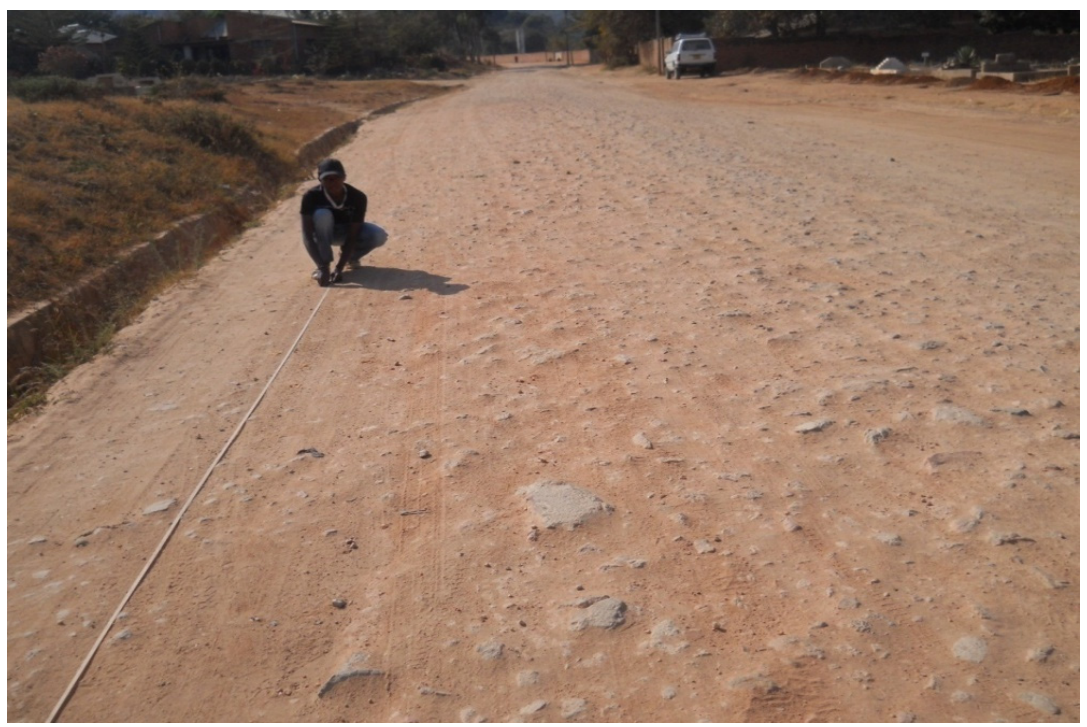

Figure 3: Stoniness embedded on Don-Bosco road.

\section{Conclusions and recommendation}

In general, test results of GC for all the marginal gravel materials borrow pits employed to surface test sections did not meet the requirement as per TZ-MoW [7]. Despite not meeting the stated specifications, these materials performed relatively well during the condition survey. It should be noted that Figure 4 is based on South African research conducted in the nineteen eighties and reported by Paige-Green [9] with slight changes. 


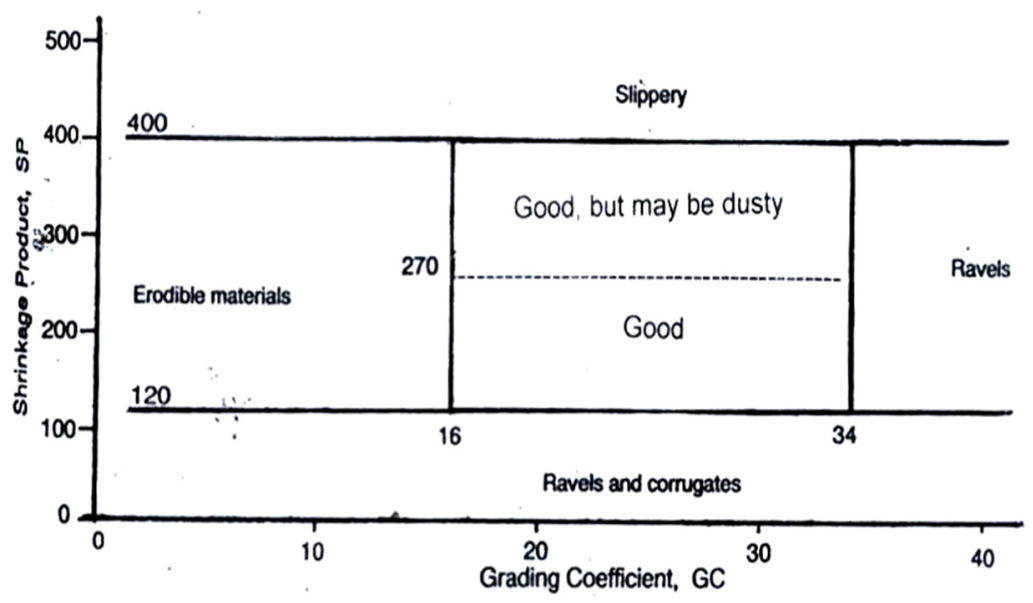

Figure 4: Performance specification for gravel wearing course.

The South African gravel road specifications were developed from roads selected using factorial design, including material types, traffic, and climate and covered a wide range of environmental conditions.

The South Africa specification has an SP range from 100-365, and GC range from 16-34. This proves further the danger of adopting directly the specification employed in other countries without doing adequate local calibration through empirical research.

From the above it is sufficient to mention here that there is a need to adjust the window frame of GC for the marginal materials as none of the distress associated with gravel materials by not meeting the given range as shown in Figure 4 were observed during the condition survey. The range for the Msembe road was 36-72, the Pawaga road was 23-62, and the Idete road 31-49. This study recommends a GC range from 23-72 for marginal materials, as it is more accommodating for all the marginal gravel materials used to surface gravel roads covered by the study.

Furthermore the study recommends that: The data base needed for identifying the factors that influence road deterioration and the effects of different maintenance processes should be substantially strengthened and refined; For a gravel road management system to be accorded high priority during annual government budget there is a need of public pressure and clear understanding of the effects of inadequate maintenance and lack of maintenance to a deteriorating gravel roads on vehicle operating and road transport costs; compilation of statistics on road condition is essential if countrywide trends are to be detected and reliable judgments made about the relative performance of each region gravel roads; standard engineering practices have very different effects in different environments, hence road investment and maintenance strategies must therefore be tailored to the circumstances of individual countries; and application of smart phones during condition survey will improve the quality of road distress data and expedite prioritisations of maintenance activities. 


\section{References}

[1] Whight, P.W., Lai, J.S., Parsonson, P.S. and Meyer, M. Highway engineering. 6th ed. John Wiley \& Sons: Singapore, 1996.

[2] Kendrick, P., Copson, M., Beresford, S. and McCormick, S. Roadwork: theory and practice. 5th ed. Heinemann: Oxford, 2004.

[3] Underwood, R. T. Road engineering practice. MacMillan Education: South Melbourne, 1995.

[4] Michigan Technological University. Pavement condition survey: module 5 Online. www.cce.mtu.edu/ce 504/Lec 4A.pdf.

[5] Jones, D. and Paige-Green, P. TMH 12: Pavement management systems: Standard visual assessment manual for unsealed roads (SANS 3012). CSIR Transportek: Pretoria, 2011.

[6] Pearson, D. Deterioration and maintenance of pavements. London: Institute of Civil Engineering (ICE) (Thomas Telford), 2012.

[7] The United Republic of Tanzania; Ministry of Works. Pavement and materials design manual. Skjetten: Novum Grafisk AS, 1999.

[8] Alzubaidi, H. and Magnusson R. Deterioration and rating of gravel roads. state of art Online. www.tandfonline.com.

[9] Paige-Green, P. Appropriate roads for rural access. In: Proceedings of the 3rd Gulf Conference on Roads. Muscat, 6-8 March 2006. Muscat: Gulf Conference on Roads, pp. 1-10, 2006. 